\title{
An Organizational Framework for Sexual Media's Influence on Short-Term Versus Long-Term Sexual Quality
}

\author{
Nathan D. Leonhardt \\ Brigham Young University - Provo \\ Travis J. Spencer \\ Utah State University \\ Mark H. Butler \\ Brigham Young University - Provo, mark.butler@byu.edu \\ Alex C. Theobald \\ Utah State University \\ Follow this and additional works at: https://scholarsarchive.byu.edu/facpub \\ Part of the Other Social and Behavioral Sciences Commons
}

\section{Original Publication Citation}

Leonhardt, N. D., Spencer, T. J., Butler, M. H., Theobald, A. C. (2018). An organizational framework for sexual media's influence on sexual quality. Archives Of Sexual Behavior, 1-17. Advance online publication.

\section{BYU ScholarsArchive Citation}

Leonhardt, Nathan D.; Spencer, Travis J.; Butler, Mark H.; and Theobald, Alex C., "An Organizational Framework for Sexual Media's Influence on Short-Term Versus Long-Term Sexual Quality" (2018). Faculty Publications. 4473.

https://scholarsarchive.byu.edu/facpub/4473

This Peer-Reviewed Article is brought to you for free and open access by BYU ScholarsArchive. It has been accepted for inclusion in Faculty Publications by an authorized administrator of BYU ScholarsArchive. For more information, please contact ellen_amatangelo@byu.edu. 


\title{
An Organizational Framework for Sexual Media's Influence on Short-Term Versus Long-Term Sexual Quality
}

\author{
Nathan D. Leonhardt ${ }^{1} \cdot$ Travis J. Spencer $^{2} \cdot$ Mark H. Butler $^{1} \cdot$ Alex C. Theobald $^{2}$
}

Received: 12 September 2016 / Revised: 27 March 2018 / Accepted: 27 March 2018 / Published online: 16 July 2018

(c) Springer Science+Business Media, LLC, part of Springer Nature 2018

\begin{abstract}
Although research has suggested a net negative influence of sexual media on sexual quality, enough researchers have found results suggesting that sexual media has no effect or a positive influence that the matter warrants further investigation. We present an organizational framework utilizing primarily the acquisition, activation, application model (3AM), and the Antecedents-ContextEffects model (ACE) to reconcile these apparently contradictory claims. By synthesizing these theories, we suggest that to truly understand the impact of sexual media on sexual quality, four factors must be taken into account: (1) the content of the sexual media being viewed, (2) the difference between short-term and long-term sexual quality, (3) the influence of exclusivity, formativeness, resonance, and reinforcement in moderating the extent to which the portrayed sexual script is applied (influences attitudes and behavior), and (4) the couple context for congruency of use, script application, and moral paradigms. While acknowledging the many nuances that should be considered, we ultimately argue that when considering these factors simultaneously, the overall scripts presented in sexual media are congruent with pursuing factors for short-term sexual quality and incongruent with pursuing factors for long-term sexual quality.
\end{abstract}

Keywords Pornography $\cdot$ Sexual media $\cdot$ Script theory $\cdot$ Sexual satisfaction $\cdot$ Sexual quality

\section{Introduction}

The pervasiveness of sexual media is well documented, as $70 \%$ of men and $40 \%$ of women report some explicit sexual media use in a given year (Regnerus, Gordon, \& Price, 2016), and $93 \%$ of young men and $62 \%$ of young women report exposure to internet pornography before turning 18 years old (Sabina, Wolak, \& Finkelhor, 2008). This pervasiveness has led many to question what impact sexual media might have on the sexual relationship, as growing consensus suggests sexual media can impact sexual attitudes and behavior (e.g., Braithwaite, Coulson, Keddington, \& Fincham, 2015; Leonhardt \& Willoughby, 2018; Wright, 2011), which can then influence sexual quality (e.g., Colson, Lemaire, Pinton, Hamidi, \& Klein, 2006; Stulhofer, Busko, \& Landripet, 2010). Although consensus is growing for sexual media's potential indirect influence on sexual quality,

Nathan D. Leonhardt

nathan_leonhardt@byu.edu

1 School of Family Life, Brigham Young University, 2081 JFSB, Provo, UT 84602, USA

2 Marriage and Family Therapy, Utah State University, Logan, UT, USA debate continues as to whether this influence is for better or for worse.

Extant reviews of the literature predominantly suggest that use of sexual media has a negative influence on sexual quality (e.g., Ward, 2016; Wright, Tokunaga, Kraus, \& Klann, 2017b), with researchers suggesting mechanisms such as objectification of a partner (Vandenbosch \& Eggermont, 2012; Zurbriggen, Ramsey, \& Jaworski, 2011) and higher interest in attractive alternatives to the relationship (Lambert, Negash, Stillman, Olmstead, \& Fincham, 2012). Yet enough researchers have found divergent results (e.g., Hald \& Malamuth, 2008; Kohut, Fisher, \& Campbell, 2017; Muusses, Kerkhof, \& Finkenauer, 2015) that examining these findings warrants careful attention. Specifically, some research suggests that sexual media is used primarily for entertainment, with little consequence from use (Kohut et al., 2017). Other research suggests that use of sexual media can positively impact couples' sexual relationship as a constructive sexual educator, providing new sexual practice ideas to sustain sexual interest and satisfaction (Daneback, Traeen, \& Mansson, 2009; Kohut \& Fisher, 2013; Kohut et al., 2017; Olmstead, Negash, Pasley, \& Fincham, 2013).

Our goal is to reconcile and expand on the reasons for discrepancies in reported harms, no effects, and benefits of sexual 
media. We present an organizational framework focused on (1) a typology of varying sexual media content, (2) the congruence of our identified types of content with pursuing factors for both short-term and long-term sexual quality, (3) the moderating influence of variables affecting sexual script application, (4) and the moderating influence of the couple context. Within this framework, we seek a more holistic understanding of the impact that viewing different types of sexual media might have on several facets of sexual quality.

We first synthesize previous research (Hald \& Štulhofer, 2016; Leonhardt \& Willoughby, 2017; Willoughby \& Busby, 2016) in creating a typology of sexual media. Our typology is formed from three different types of sexual media content: sexually suggestive media (non-explicit media that depicts a person in a sexually provocative way), sexually explicit media (media depicting explicit sexual acts), and paraphilic sexual media (depiction of explicit sexual behavior that includes dominance, coercion, or fetishes).

Second, we use Fisher's (1998) work on sexual motivation to differentiate between several factors for short-term and longterm sexual quality. We then explain the extent that the content from our identified types of sexual media are congruent or incongruent with the pursuit of our identified factors. We argue that each type of content differs in congruence with factors for short-term and long-term sexual quality. Yet holistically, each type of content presents messages congruent with short-term sexual quality and incongruent with long-term sexual quality.

Third, we appeal heavily to Wright's (2011) 3AM model by evaluating the moderating role of sexual script application (the extent to which sexual scripts actually influence attitudes and behaviors). We specifically discuss how several moderating factors (i.e., exclusivity, formativeness, resonance, and reinforcement) can influence the extent to which the script is attitudinally and behaviorally applied.

Finally, we consider how these understandings of sexuality influence sexual quality when individuals with varying sexual scripts engage in sexual activity. We appeal to the recently suggested Antecedents-Context-Effects Model (ACE; Campbell \& Kohut, 2017) to further evaluate how couple contextual factors (congruency of sexual media use, script application, and moral paradigms) impact the role that sexual media has on sexual quality.

Ultimately, we argue that the scripts presented in our sexual media typology present messages congruent with short-term sexual quality and incongruent with long-term sexual quality. We also argue that sexual script application and the couple's context of use must be considered as moderators to fully understand these links. By considering the actual content in various sexual media types, several factors in distinguishing between short-term and long-term sexual quality, and multiple layers of moderators, we believe our model provides the most comprehensive framework to date for how and why sexual media use influences sexual quality (see Fig. 1).

\section{Content Analysis of Sexual Media}

One of the biggest weaknesses in research on sexual media is measurement that disregards the actual message portrayed in the content. For example, some scholars have noted that there is no standard definition for pornography (Daneback et al., 2009; Kohut, 2014; Short, Black, Smith, Wetterneck, \& Wells, 2012), and that what is considered pornographic is highly dependent on the values and responses of its viewer (Willoughby \& Busby, 2016). Combined with the lack of a standard definition for sexual content, many researchers have used a single-item measure, asking participants how often they have used sexual content over an allotted period of time (Short et al., 2012). These non-ideal measurement conditions could produce significant variability in respondents' frame of reference when answering questions. For example, although people primarily agree that pornographic content involves explicit sexual acts (Kohut, 2014; Willoughby \& Busby, 2016), it is still possible that reports of pornography use could range from a sexually suggestive magazine to graphic depictions of group sex (Willoughby \& Busby, 2016). Seeing the weakness of the single-item measure in assessing sexual content, both Hald and Stulhofer (2016) and Willoughby and Busby (2016) have called for a more multidimensional approach in measuring the sexual content being viewed by research respondents. This multidimensional approach is crucial to understanding how sexual media influences sexual quality, as different depictions in content likely differ in how they shape sexual attitudes and behaviors.

Utilizing a more multidimensional approach proves difficult, as there are innumerable possibilities of sexual scenarios depicted in sexual media. Attempting an all-encompassing typology would likely be so convoluted that it would lack practicality for research, clinical practice, education, and public policy. However, there is some work suggesting that while certain sexual content has overlapping qualities, it is possible to distinguish between some broad types of sexual media for research purposes (Hald \& Štulhofer, 2016; Leonhardt \& Willoughby, 2017; Willoughby \& Busby, 2016). For our purpose, we synthesize work differentiating suggestive sexual media from explicit sexual media (Leonhardt \& Willoughby, 2017; Willoughby \& Busby, 2016), and explicit sexual media from paraphilic sexual media (Hald \& Štulhofer, 2016; Stulhofer et al., 2010), to create a rough typology based on validated empirical constructs. Some research has already begun to show how these differing types of media have differential associations with sexual quality (Leonhardt \& Willoughby, 2017; Stulhofer et al., 2010). Throughout this article, when referring to all three of these types of media, we use the term "sexual media" rather than "pornography" or "sexually explicit material."

Scripts consistently portrayed through each type of content include eroticism ("pursuit and delight in sensual pleasure" 


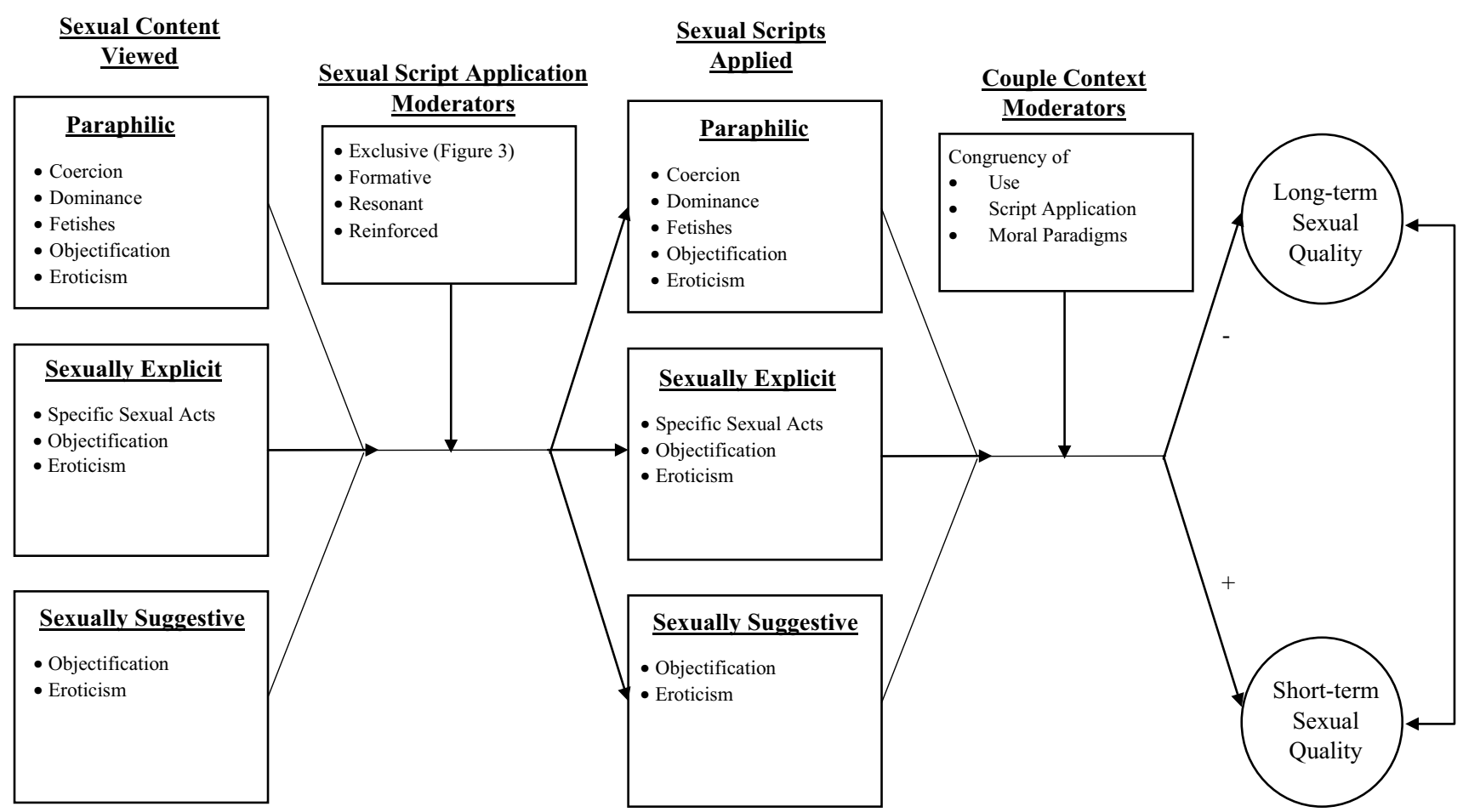

Fig. 1 How viewing sexual media influences sexual quality. Influence is moderated by both the application of sexual scripts and the couple context

Schnarch, 1991, p. 314) and objectification ("whenever people's bodies, body parts, or sexual functions are separated out from their identity, reduced to the status of mere instruments" Fredrickson, Roberts, Noll, Quinn, \& Twenge, 1998, p. 269). The biggest distinction between sexually suggestive media and sexually explicit media is that the sexually explicit media depicts sexual acts (Leonhardt \& Willoughby, 2017; Willoughby \& Busby, 2016). The biggest distinction between the paraphilic sexual media and the other types of media is the display of dominance, coercion, or fetishes (Hald \& Štulhofer, 2016).

\section{Suggestive Sexual Media}

Despite the wide variability in use of the term "eroticism" (e.g., Elise, 2017; McCarthy \& Thestrup, 2009; Newmahr, 2014; Rind, 2015), the term is consistently related to physical sensation and is often used in reference to sexual desire, arousal, and pleasure (e.g., McCarthy \& Thestrup, 2009; Schnarch, 1991). Evidence suggests that eroticism is one of the major scripts presented in sexually suggestive media, as some research has found that the most prominent message in popular magazines for "great sex" is a focus on technical/mechanical/physical factors (Menard \& Kleinplatz, 2008).

Another common script in sexually suggestive media is objectification. In a review of the literature, Ward (2016) found that women were frequently objectified in music videos (Frisby
\& Aubrey, 2012), magazine ads (Stankiewicz \& Rosselli, 2008), and video games (Burgess, Stermer, \& Burgess, 2007). Men are also objectified nearly as often as women in magazines (Hatton \& Trautner, 2011). However, some research suggests they are objectified less in television commercials (Prieler \& Centeno, 2013) and video games (Burgess et al., 2007). In summary, sexually suggestive media presents a message focused on the pursuit of physical pleasure in sexuality, but also tends to separate individuals' body parts and sexual function from their identity, emotions, and relationships (particularly for women).

\section{Explicit Sexual Media}

Explicit sexual media also portrays scripts of eroticism and objectification. Content analyses have evaluated mainstream pornographic scenes, and although they do not code specifically for "eroticism," the analyses suggest that the content has a focus on physical pleasure and excitation from the sexual response (Fritz \& Paul, 2017; Klaassen \& Peter, 2015). The research on objectification in sexually explicit media is less extensive than for sexually suggestive media, with some who hold a more stringent definition of objectification suggesting that it may be relatively uncommon (McKee, 2005). However, multiple content analyses have suggested that components of objectification (e.g., instrumentality, dehumanization) are a common occurrence in sexually explicit media for both genders (Klaassen \& 
Peter, 2015), with possibly a greater focus on women (Fritz \& Paul, 2017).

One of the biggest distinguishing features between explicit sexual media and suggestive sexual media is the depiction of sexual acts (Leonhardt \& Willoughby, 2017; Willoughby \& Busby, 2016). Content analyses have shown some consistency in suggesting the typical acts portrayed in mainstream pornography (e.g., vaginal sex, oral sex), but some discrepencies in findings also exist (e.g., nature and level of aggression; Bridges, Wosnitzer, Scharrer, Sun, \& Liberman, 2010; McKee, 2005, 2015). However, the specificity in prevalence of specific acts is not imperative in relation to our larger argument. By and large, a multiplicity of sexual acts are part of the depictions of explicit sexual media (Bridges et al., 2010; Fritz \& Paul, 2017; Klaassen $\&$ Peter, 2015), while in this type of sexual media paraphilic depictions (described below) are not present.

\section{Paraphilic Sexual Media}

Like the previous types of media, paraphilic sexual media contains scripts of eroticism, objectification, and specific sexual acts. It also adds portrayals of fetishes, coercion, and dominance, thereby distinguishing it from explicit mainstream sexual media (e.g., Bridges et al., 2010; Hald \& Štulhofer, 2016; Klaassen \& Peter, 2015). Content analyses indicate that the paraphilic category of sexual media is relatively uncommon (likely $<10 \%$ of mainstream pornographic scenes; Bridges et al., 2010; Klaassen \& Peter, 2015). Self-report data also support this notion, as one study of 1107 respondents found that only $6.6 \%$ of men $(n=8)$ and $9.7 \%$ of women $(n=15)$ reported using sexual content that showed harm or degradation (Bridges \& Morokoff, 2011).

\section{Summary}

A major weakness of the current literature surrounding sexual media and sexual scripts is failing to account for differing types of content portrayed in the media. Suggestive sexual media, explicit sexual media, and paraphilic sexual media have many similarities, but also have identified differences which could impact their differential influence on sexual scripts. We assert that utilization of this typology is important to consider when evaluating the impact of sexual media on sexual quality, as different types of content influence attitudes and behaviors surrounding sexuality in different ways.

\section{Sexual Quality}

Evidence continues to grow showing that sexual media's portrayal of sexual scripts influences attitudes and behavior surrounding sexuality (Braithwaite et al., 2015; Leonhardt \& Willoughby, 2018; Wright, 2011), which in turn influences sexual quality (e.g., Colson et al., 2006; Stulhofer et al., 2010). However, as we have noted, studies of sexual media fail to account for the type of sexual media respondents are commenting on. A similar measurement problem exists in relation to sexual quality. The most common assessment of overarching sexual quality is the construct sexual satisfaction. One limitation of focusing predominantly on an overarching measure of sexual satisfaction is that the construct often enlists vague, global definitions assessing the subjective appraisal of one's sexual relationship (McClelland, 2010), along with few conceptual definitions, few theoretical models, and inconsistency in the indicators used in different measures of sexual satisfaction (Pascoal, Narciso, \& Pereira, 2014).

This is problematic because sexual quality is a multidimensional phenomenon that potentially plays out differently across time, yet is measured and reported as though it were monolithic (e.g., Kleinplatz et al., 2009; Pascoal et al., 2014). For example, someone can report being highly satisfied from a sexual experience that was a one-night stand, or from a sexual experience with a spouse after 20 years of marriage. Our typical monolithic valuation of sexual quality treats these separate scenarios of high satisfaction in the same way, despite the possibility that the participants' "satisfaction" from these experiences is qualitatively dissimilar. We suggest that to truly understand the association between viewing sexual media and sexual quality, sexual quality also needs to be discriminated as a multifaceted phenomenon and evaluated over both the short term and long term. We suggest that when we consider the multifaceted nature of both sexual content and sexual quality, the scripts presented in sexual media are congruent with the pursuit of aspects of sexual experience connected primarily to short-term sexual quality, while simultaneously being incongruent with aspects connected primarily to long-term sexual quality.

\section{Short-Term Versus Long-Term Sexual Quality}

In assessing the congruency of sexual scripts with sexual quality, a critical distinction must be entered into the evaluation, namely short-term and long-term sexual quality appears to derive from different motivational systems in the brain that are adapted to different conditions and functions (e.g., Fisher, 1998; Fisher, Aron, Mashek, Li, \& Brown, 2002; Jackson \& Kirkpatrick, 2007). Fisher (1998) suggested that sexual drive is the motivation correlating primarily to short-term sexual relationships, whereas romantic attraction and attachment seem more focused on long-term sexual relationships.

Short-term sexual quality seems connected to the sexual drive motivation. The gratification of sexual drive is indiscriminate of person and often serves as an initial motivator in seeking out a wide range of potential partners. Those engaging in short-term sexual experiences seem less likely to focus on affectionate connection and concern for the partner's 
sexual well-being (Schachner \& Shaver, 2004). These individuals need not concern themselves with their partner's sexual desires because they are more concerned with satisfying a physical appetite than the emotional and relational aspects of the sexual experience (Jackson \& Kirkpatrick, 2007). Holistically, the short-term sexual motivation focuses more closely on gratification (Lofgren-Martenson \& Mansson, 2010), novelty (Morton \& Gorzalka, 2015), pleasure (Grubbs, Braden, Kraus, Wilt, \& Wright, 2017), and has little concern with a partner's identity (Fisher, 2006),

Conversely, long-term sexual quality seems more connected to motivational systems of romantic attraction and attachment to a specific sexual partner. Romantic attraction is what helps someone to focus their sexual interest on a specific individual, often leading them to commit to an exclusive relationship (Fisher, 1998). The partner becomes "special" to the individual and cannot be replaced by any alternative sexual partner. The attachment motivational system is a more enduring bond that helps keep couples together and is focused more on the emotional and relational elements of sexuality (Fisher, 1998). Couples typically develop this bond over an extended period, gradually developing trust as they are reliably responsive and alleviate each other's distress in troubled times (Cooper et al., 2006; Mikulincer \& Shaver, 2016). Together these more long-term oriented sexual motivation systems seem connected to a craving for emotional union (Schachner \& Shaver, 2004), social connection (Baumeister $\&$ Tice, 2001) and an increased calm, comfort, affection, and feeling of care for the well-being of the partner (e.g., Fisher, 1998; Fisher et al., 2002).

The motivations of sexual drive, attraction, and attachment are intertwined in unique ways, and certainly influence each other (e.g., Crawley \& Mclean, 1996; Herbert, 1996). However, it is also possible for these motivations to combine and attach to different individuals in distinct ways, as one measurement study provided evidence suggesting short-term and long-term sexual motivations are distinct constructs (Jackson \& Kirkpatrick, 2007). We suggest that short-term sexual quality appears more strongly linked to the erotic dimension of sexuality, focused on novelty, pleasure, and gratification, which may be developed independently of any relational element of the sexual experience. Alternatively, long-term sexual quality appears more closely linked to the intimate emotional and relational dimensions of sexuality, with one's own and the partner's identity being paramount to the sexual experience.

Building off the theoretical work of Fisher (1998), we have selected a sampling of constructs (e.g., Frost, McClelland, \& Dettmann, 2017; Kleinplatz et al., 2009; Muise, Impett, Kogan, \& Desmarais, 2013; Pascoal et al., 2014) that we believe help illustrate the distinction between short-term and long-term sexual quality. These factors are distinguished by whether they are primarily oriented toward immediate sexual gratification or long-term sexual connection. We suggest short-term sexual quality is connected primarily to factors such as sexual openness (feeling at ease and without inhibition in sexual interaction; Pascoal et al., 2014), arousal (experiencing physical excitation; Pascoal et al., 2014), and sexual technique (a repertoire of knowledge for sexual positions, strategies, etc.; Pascoal et al., 2014). We suggest longterm sexual quality is connected primarily to factors such as sexual communal strength (motivation to be non-contingently responsive to a partner's sexual needs; Muise et al., 2013), sexual intimacy (a closeness and connectedness between partners, built upon a shared vulnerability and a developed relational identity; Frost et al., 2017; Kleinplatz et al., 2009; Montesi et al., 2013), and sexual communication (exchanging information about the sexual experience through symbols, signs, or behavior; Kleinplatz et al., 2009; Pascoal et al., 2014). We note that these factors should be considered illustrative rather than comprehensive for distinguishing between short-term and long-term sexual quality.

By evaluating specific sexual quality constructs, it becomes easier to assess consistencies and inconsistencies between sexual scripts portrayed and the desired sexual outcome. We illustrate this point by giving a more in-depth description of these sexual quality factors, and by analyzing the extent to which the content of our sexual media types is congruent with pursuing these factors (see Fig. 2).

\section{Short-Term Sexual Quality}

\section{Sexual Openness}

Pascoal et al. (2014) described sexual openness as being an individual characteristic, not contingent on a sexual partner. This fits our description of a factor for short-term sexual quality because it can exist independent of any developed relational element of sexuality. The erotic script from our sexual media types focuses on personal, sensual pleasure (Klaassen \& Peters, 2015). This preoccupation with sexual sensuality scripts sexual openness free of inhibitions and restraints, for the pursuit of gratification. Each type of sexual media normalizes sexual openness. It is not surprising, then, that previous research has suggested that exposure to sexual media decreases sexual anxiety and thereby plays a role in reducing inhibitions (Fyfe, 1979; Kohut et al., 2017; Nemetz, Criag, \& Reith, 1978; Weinberg, Williams, Kleiner, \& Irizarry, 2010).

\section{Sexual Arousal}

Sexual arousal is another individual element of sexual experience that can be independent of any relational context or development, thus fitting under the umbrella of short-term sexual quality. Individuals certainly experience sexual arousal in longterm sexual relationships, yet they can also experience sexual arousal from a one-night stand or after dating for a couple of 


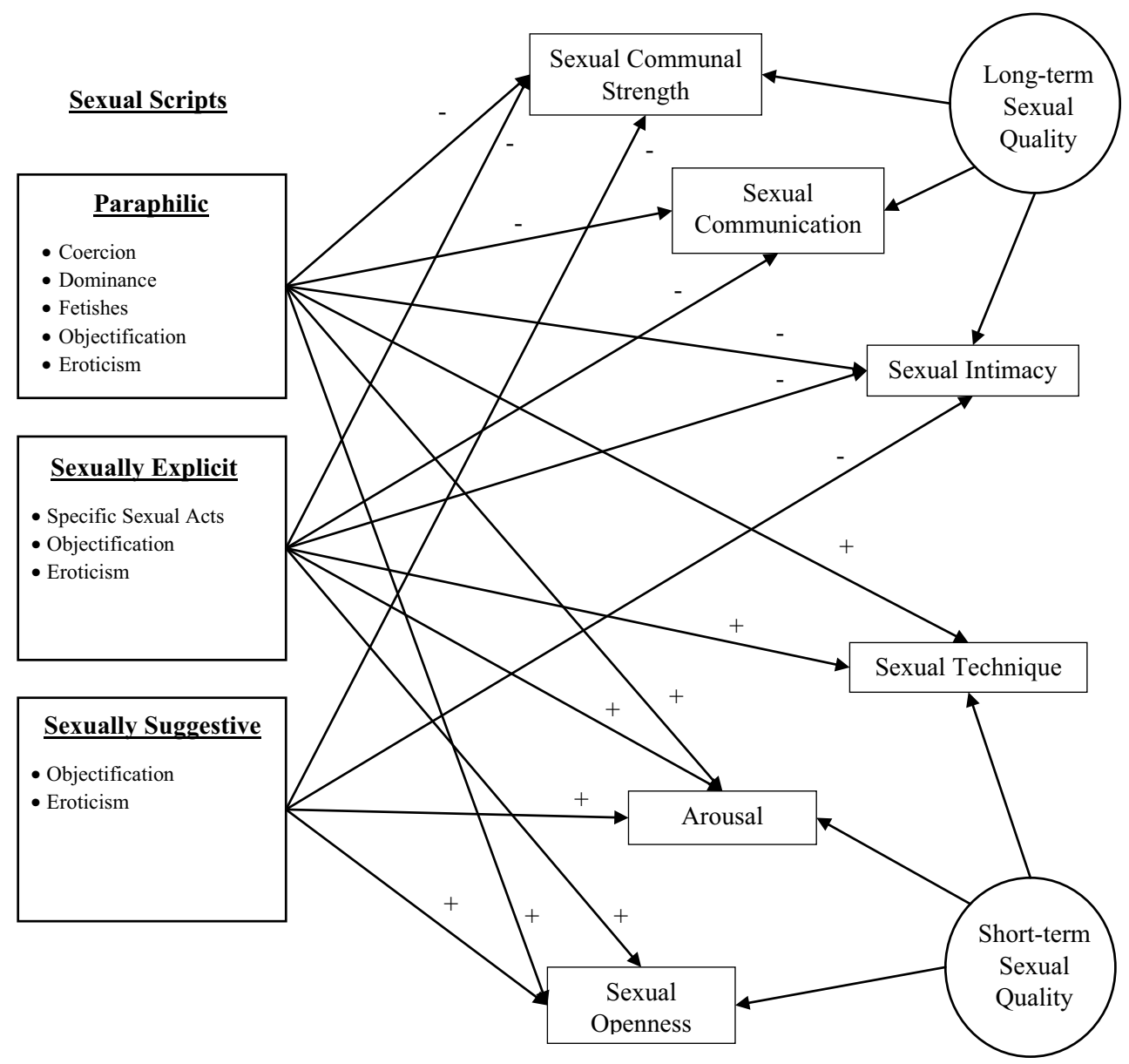

Fig. 2 The congruence and incongruence of sexual media types with several factors for short-term and long-term sexual quality. Note Plus signs indicate congruence of script and outcome. Minus signs indicate

weeks. By presenting a script of eroticism through exciting, sexualized images, all types of sexual content likely contribute to heightened levels of arousal and physiological rewards from the sexual experience (e.g., Kohut et al., 2017; Prause \& Pfaus, 2015). As a whole, the scripts from each type of sexual content all emphasize eroticism and are congruent with personal sexual arousal. However, the explicit nature of both sexually explicit media and paraphilic sexual media may suggest that the scripts from those types have the strongest linkage with the sexual arousal aspect of sexual quality.

\section{Sexual Technique}

Use of sexual media is often reported as a way to "spice up" the sexual relationship or discover novel techniques for obtaining sexual pleasure (Kohut et al., 2017; Olmstead et al., 2013). Sexual technique is slightly more dyadic in nature, but still fits as a factor for short-term sexual quality because it is an individualized trait that is carried with someone independent of the incongruence of script and outcome. Multiple paths are omitted to indicate a lack of connection between the type of media script and the indicator for sexual quality

relationship. If someone were to end a sexual relationship, they would retain knowledge of various sexual techniques that could be employed in other relationships.

Among the short-term factors of sexual quality, sexual technique is one of the clearest examples for the importance of considering the type of content portrayed in sexual media, as the script displayed can influence which scripted behaviors someone will desire to enact (Kohut \& Fisher, 2013). For example, sexually suggestive media does not have a script congruent or incongruent with the development of sexual technique because it does not portray any sexual acts. Conversely, both explicit sexual media and paraphilic sexual media present explicit sexual acts, making the scripts congruent with attaining knowledge of sexual technique. Research supports the idea that viewing specific sexual acts can increase the likelihood of imitating the act (Kohut \& Fisher, 2013), suggesting that sexual media can present scripts that increase experimentation with newly identified sexual practices. 


\section{Long-Term Sexual Quality}

\section{Sexual Communal Strength}

The concept of sexual communal strength was theoretically conceived by Muise et al. (2013) from broader work on communal relationships (Clark \& Mills, 2012) and approach-avoidance theories of motivation (Gable \& Impett, 2012). Muise and Impett (2015) found that sexual communal strength predicted higher committed partners and higher perceived partner responsiveness to sexual needs. These findings illustrate the long-term relational element of sexual communal strength, through emotional and relational ties to a specific partner.

Our identified types of sexual media do not portray the importance of non-contingently meeting a partner's sexual needs and therefore do not elicit the sexual script of sexual communal strength. In fact, the script of objectification in each type of sexual media presents a script incongruent with sexual communal strength, mainly through instrumentation, or portraying a partner as a means to attain personal pleasure, rather than focusing on an inclination to sexually satisfy a partner (e.g., Klaassen \& Peter, 2015; Ward, 2016). Specifically, in explicit sexual media, over $90 \%$ of scenes for both men and women portray sex as being primarily for self-pleasure (Klaassen \& Peter, 2015). Paraphilic sexual media may have even less congruence to sexual communal strength than the other types of media, as the scripts of dominance and coercion (Hald \& Štulhofer, 2016) suggest a particular lack of regard for a sexual partner's desires.

\section{Sexual Intimacy}

Sexual intimacy is another specific dyadic factor that fits under the umbrella of long-term sexual quality. Intimacy is a relational dimension of sexuality that can only be developed and experienced over the long term, as it is a reciprocal and interactive process (e.g., Berg \& Derlgega, 1987; Reis $\&$ Shaver, 1988). True sexual intimacy is developed from a shared history, best established from the trust and security accompanying a sense of permanence to the relationship.

Each type of sexual media (suggestive, explicit, paraphilic) presents a script incongruent with sexual intimacy. Focusing on eroticism, without any relationship development, our suggested sexual media types inaccurately suggest that intimacy develops quickly, without much effort or emotional vulnerability. Sexual media's script of objectification (e.g., Klaassen \& Peter, 2015; Ward, 2016) is also problematic; based on our description of both intimacy and objectification, it could be argued that objectification is an antithesis of intimacy, as objectification depicts sexuality without identity (Bridges et al., 2010; Conley \& Ramsey, 2011; Klaassen \& Peter, 2015; Stankiewicz \& Rosselli, 2008). Similar to sexual communal strength, paraphilic sexual media presents a script particularly incongruent with the development of intimacy, as its depictions of coercion and dominance focus on exploiting a sexual partner for personal gratification, rather than on achieving closeness and connectedness between partners.

\section{Sexual Communication}

Sexual communication reflects a couple process (Kleinplatz et al., 2009; Pascoal et al., 2014), occurring within the context of the sexual relationship, where the things learned within one relationship do not necessarily apply to any other sexual relationship. Overall, sexual communication fits more appropriately under the umbrella of long-term sexual quality since sharing and receiving subtle, almost imperceptible nonverbal cues in communication is a highly nuanced, almost intuitive, pre-cognitive experience for many couples (Kleinplatz et al., 2009) and only develops over time.

Because suggestive sexual media does not display sexual interaction between partners, it is unlikely to present a script congruent or incongruent with sexual communication. However, content analyses of sexually explicit media suggest a portrayal of non-ideal sexual communication, as this type of media typically includes the message that everything feels good and there is never a need to communicate about what might not be pleasurable, comfortable, or affirming for either partner (Bridges et al., 2010; Klaassen \& Peter, 2015). For paraphilic sexual media, the inclusion of coercion and dominance (Hald $\&$ Štulhofer, 2016) could suggest a particular lack of responsive communication within the dyad.

\section{Summary}

Our theoretical framework can be a springboard for empirical investigations that will carefully differentiate the complex, multifaceted nature of sexual quality. Altogether, we propose that erotic factors-sexual openness, arousal, sexual technique-are key factors more congruent with the pursuit of short-term sexual quality, whereas emotional and relational factors-sexual communal strength, sexual intimacy, and sexual communication - are factors more congruent with the pursuit of long-term sexual quality. Some variation exists in the extent to which different types of sexual media may influence different aspects of short-term and long-term sexual quality, but altogether the sexual scripts portrayed in each type of sexual media we have outlined seem to enhance the pursuit of short-term sexual quality and impede the pursuit of long-term sexual quality.

We also note that although we have offered a rationale for how these different types of sexual media may influence different aspects of sexual quality by the way they influence sexual attitudes and behaviors, some research findings offer an alternative perspective (Kohut et al., 2017). For example, while we suggest that use of our identified types of sexual media is generally congruent with pursuing arousal and incongruent with pursuing 
intimacy, some research has found diverging results (e.g., Bronner \& Ben-Zion, 2014; Kohut et al., 2017). Our acknowledgment of moderators will go into greater depth on some potential reasons for conflicting findings.

\section{Application of Sexual Scripting}

We have pointed out the weaknesses in measurement and conceptualization for both sexual media and sexual quality. We have also shown a theoretical connection between multiple types of sexual media and how their scripts may or may not be congruent with various aspects of short-term versus long-term sexual quality. However, several mechanisms moderate sexual media's influence.

Sexual media scripts are influential toward sexual quality to the extent that they are applied, meaning the extent that they actually influence attitudes and behaviors (Wright, 2011). Wright's 3AM model incorporated ideas from information processing theory (see Huesmann, 1988), cultivation theory (see Gerbner, 1998), and conditioning theories (see Bandura, 1977; Pavlov, 1927; Skinner, 1938) to suggest several moderators in the likelihood of sexual scripts influencing attitudes and behaviors. We do our best to succinctly synthesize some of the most important factors from the $3 \mathrm{AM}$ model in making our argument.

Broadly, sexual scripts are more likely to be applied when they are (1) exclusive (a predominant exposure shaping sexual scripts in the comparative absence of countervailing scripting sources), (2) formative (early age of exposure or the first source of information), (3) resonant (are congruent with real-life experience), and/or are (4) reinforced (the viewer receives positive reinforcement from enacting the script). Alternatively, the early arrival, persistent presence, and reinforcement of other scripting sources can result in a lower likelihood of sexual media script application (Wright, 2011), and in turn the attitudes and behavior set forth from sexual scripts may be less likely to influence sexual quality (e.g., Colson et al., 2006; Stulhofer et al., 2010).

\section{Exclusivity}

Sexual scripts are shaped from a multiplicity of influences and experiences (Gagnon \& Simon, 1973; Wright, 2011). Any particular scripting source may manifest definitive themes, values, and so forth; through the convergence of multiple sources, an amalgamated sexual script develops. The resulting amalgamation is not necessarily coherent, but may contain numerous internal inconsistencies and contradictions. Finally, the comparative influence of various scripts varies across individuals, based on how influential the source is. Script sources include (1) one's family, (2) peers, (3) romantic partners, (4) and media (see Fig. 3). Primarily, these influences make up the lens through which an individual understands sexuality and within which her or his sexual script is developed (Steele, 1999). Although these four sources are not an exhaustive list of all factors in one's script formation, they do capture major focal points from which we can examine one's development.

Although the process of script formation is complex and diverse, there are general spheres of influence that are common in scripting experience. It is also helpful to consider the continuity or fluidity of different sources of sexual influence throughout one's development. Although sources of sexual scripting may change over time, the spheres of influence themselves - peer, romantic, familial — continue to exist and influence development. For example, while a child may initially rely on the parents' understanding of sexuality during early development, the child's understanding will eventually be significantly influenced by peers as well. The presence of another source changes the amount of influence the initial source has on a child's development (Steele, 1999; Wright, 2011). Regardless of how or when sources become more or less influential, each sphere of influence persists. Through these persistent spheres of influence, understandings of sexuality are shaped into a global script. Again, the resulting script may not be entirely coherent or consistent, informed as it often is by multiple, possibly conflicting sources. These conflicting sources may mitigate the influence of sexual media by providing countervailing scripts, or may exacerbate its influence if other sources send a message congruent with the script from sexual media.

\section{Formativeness}

Studies show that the first source of information on sexuality often most significantly informs expectations and preferences concerning sexuality (Pfaus et al., 2012; Pfaus, Scepkowski, Marson, \& Georgiadis, 2014; Wright, 2011). The earlier children and adolescents are exposed to a sexual script, the greater likelihood that source will imprint itself and prove more resistant to change over an extended period of time. Although understandings of sexuality constantly change through this process, a formative understanding of sexuality often takes place in the early stages of one's development (Pfaus et al., 2012; Steele, 1999). Although information regarding sexuality may not shape preferences and expectations as strongly as sexual experience itself (Pfaus et al., 2012), the family still has a strong initial influence for understanding and interpreting sexuality due to often being the first source of information.

Research suggests that when the family is a person's primary sexual scripting source, it can mitigate the influence of sexual media (e.g., Rasmussen, Ortiz, \& White, 2015; Starr \& Ferguson, 2012). For example, an individual who has parents who are open to and comfortable when talking about sexuality provide that individual with a lens through which to interpret sexual media. When the individual views sexual media, he or she may critique the reality of the situations displayed, being aware of what factors are important for a healthy sexual relationship and comparing that to the content observed. This comparison gives 
Fig. 3 Model of script sources. Double-sided arrows were used to acknowledge that while all these sources influence the formation of a sexual script, the sexual script also can influence interactions with each of these sources of information. Note We do not claim this is an exhaustive depiction of sexual scripting sources. The figure is intended to be illustrative

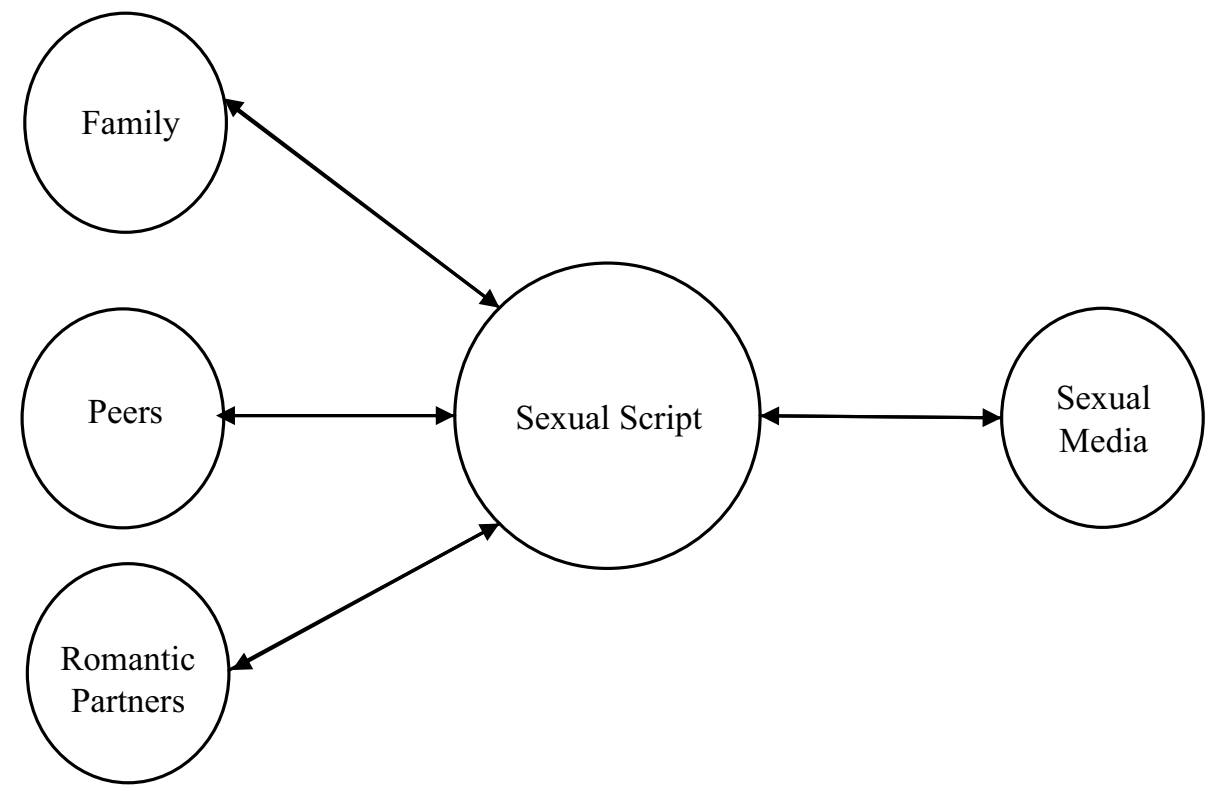

the individual pause and an opportunity to observe the situation, asking such questions as, "If my father treated my mother like this, would they be happy?" "What does this kind of sexuality do in a relationship?" "What does this mean about my sexuality?" Given she or he has a trusted source to approach, a child could discuss what was seen and how this sparked a set of sexual script setting questions (Rasmussen et al., 2015; Starr \& Ferguson, 2012). Healthy exploration within primary source relationships, therefore, acts as a catalyst for the formation of sexual scripts.

We briefly note that although media has traditionally been viewed as less formative in comparison with sources such as familial relationships, there is reason to believe that the tripleA engine of pornography (affordability, availability, and anonymity; see Cooper, Delmonico, \& Burg, 2000) has resulted in sexual media increasingly serving as a source of formative development of sexual scripts-due to both pervasiveness and early access. As early age of exposure to sexual media becomes prominent (Sabina et al., 2008), more and more children receive their formative exposure to sexuality from sexual media. If, in a sexually saturated media environment, with pervasive media access, parents in turn are hesitant to openly talk about sexuality with their children (Martin \& Luke, 2010), sexual media may serve increasingly as a formative influence for prepubescent and adolescent children learning about sexuality. The age of exposure and whether sexual media is the initial source in learning about sexuality are critical in determining whether and to what extent sexual media may script sexuality and influence sexual quality.

\section{Resonance}

The concept of resonance, originally suggested by cultivation theory (Gerbner, 1998) and synthesized into the 3AM model
(Wright, 2011), suggests that when messages or scripts presented in media are congruent with the everyday realities of viewers, the media is likely to amplify cultivation of the experientially derived worldview. Equally derivable is the converse corollary: when media scripts contradict other, real-world script sources (e.g., family, peers, and romantic partners), the media script is more likely to be attenuated or rejected. Thus, although some sexual content portrays coercive or dominant behavior of men toward women (Bridges et al., 2010; Hald \& Štulhofer, 2016), if this behavior is not consistent with what the viewer experiences in reality, the viewer is less likely to accept the script as something real.

Although real-world close relationships and sexual media can both influence script development, for the individuals experiencing the relationships, one takes place in reality while media exposure remains only a viewing of some depiction of reality. Despite what sexual media might portray, real-time, not virtual experience, acts as the ultimate source of what is desirable and real. Understanding the influence of sexual media within the context of this greater, relationship-based culture more fully exposes the complex processes of mediation and moderation through which sexual media influences development. Often, family, peers, and romantic partners are more primary than sexual media in influencing the development of a sexual script, as they present real-time relationships wherein one can learn about or experience sexuality (Gerbner, 1998; Pfaus et al., 2012; Steele, 1999). For example, if one's romantic partner is sexually sensitive, responsive, and relationally oriented, it is more impactful than exposure to a media depiction of the same dynamics.

Although sexual media is a mere depiction of sexuality, technological advancements are being made to virtual sexual media, which may exaggerate the viewer's notion of the media being a depiction of "reality" (Wong, 2016). Technology enabling 
increasingly "authentic" depictions may lead the viewer to have a higher level of resonance as he or she begins to experience the virtual reality as a type of reality. It seems possible that as virtual reality technology obscures the separation between depiction and real-world experience, ability to differentiate between the two could be diminished. Still, research is needed to test this hypothesis and identify the brain's capacity to maintain a clear silo between depiction and real-world realms. Evaluating resonance in combination with formativeness may be an especially profitable area of study, as research suggests that children have greater difficulty distinguishing between fantasy and reality (Murray et al., 2006).

\section{Reinforcement}

According to Wright's (2011) 3AM model, and its synthesis of ideas surrounding conditioning (see also Bandura, 1977; Pavlov, 1927; Skinner, 1938), rewards from the sexual response have the ability to reinforce attitudes and behavior surrounding sexuality. In other words, expectations surrounding sexuality have malleability based upon experiencing rewards (Pfaus et al., 2012). This can be seen at the couple level, as a couple that participates in mutually appreciative sexual acts may reinforce each other to have certain cues surrounding the initiation of sex, acts to expect during sex, and other nuances related to the pursuit of arousal, orgasm, or conclusion of sexual activity (Pfaus et al., 2012, 2014).

On the other hand, through consistent viewing of sexual media, individuals may condition themselves to the sexual media script, producing specific sexual preferences based upon the reinforcement they have experienced through viewing the media (Pfaus et al., 2012, 2014). Especially when masturbation accompanies the viewing of sexual media, the rewards of the sexual response cycle likely have an affirming impact on the sexual script being portrayed (Pfaus et al., 2012). Reinforcement may be a particularly important moderator to consider, as its influence on sexual media use is highly unlikely to be completely eliminated. Frequency of use and masturbation may be some specific factors to consider under the umbrella of this overarching moderator.

\section{Summary}

Although we have pointed out how the scripts from sexual media are congruent with pursuing short-term sexual quality while being incongruent with pursuing long-term sexual quality, these links can be moderated, perhaps even significantly, by factors influencing script application. Some of the most salient factors moderating script application are exclusivity, formativeness, resonance, and reinforcement. Although these moderators do not eliminate the influence of sexual media use, they may substantially weaken or amplify the effect. For example, those who begin using sexual media at a later age and have alternative sources to inform them about sexuality, may have sexual media's script so attenuated that an empirical effect is difficult to detect (e.g., Wright, Sun, Steffen, \& Tokunaga, 2017a), and they report that sexual media has no effect on their sexuality (e.g., Kohut et al., 2017; Muusses et al., 2015). To better understand the extent that sexual media influences short-term or long-term sexual quality, the exclusivity, formativeness, resonance, and reinforcement of script application should be taken into account.

\section{Couple Context}

We have utilized Wright's (2011) 3AM model to note how several moderators (exclusivity, formativeness, resonance, reinforcement) may mitigate or exaggerate the likelihood of sexual media influencing our identified indicators of sexual quality. Another step remains. We have outlined how sexual media's script is congruent with short-term sexual quality factors like sexual arousal, and incongruent with long-term factors of sexual quality such as intimacy. The sexual script application moderators help explain why some report no effect. However, the script application moderators do not explain why some men report their sexual media use leads to problems with arousal by means of erectile dysfunction (e.g., Park et al., 2016; Voon et al., 2014) and some individuals report sexual media to be an enhancer of sexual intimacy (Kohut et al., 2017). To further understand conflicting results within sexual media and sexual quality literature, a layer of couple context moderators between the sexual script applied and the actual sexual outcome are needed (see second half of Fig. 1).

Campbell and Kohut (2017) provided a guiding framework in considering couple contextual factors called the Antecedents-Context-Effects Model (ACE). Some of the contextual variables they put forward include frequency of use, solitary versus joint use, and content of use. They also suggested that certain contextual factors can be directly responsible for the assumed effects of sexual media exposure, rather than the use of sexual media itself. They specifically suggested that many researchers and couples assess sexual media use through the lens of likely harms. This can lead to overlooking potentially confounding contextual variables that are the true reason for negative associations between sexual media and outcomes, rather than the use of sexual media itself. This logic also works in the inverse. Couples and researchers may misattribute positive outcomes from sexual media use and script application, when in actuality something within the couple context is responsible for the reported positive outcome.

We cannot give examples of how all contextual factors may interact with each type of sexual media in predicting short-term versus long-term sexual quality. We simply hope to use some examples to illustrate how couple context should be considered alongside the other elements of our model. We 
assert that couple congruency of (1) use patterns, (2) script application, and (3) moral paradigms are important variables to consider when ultimately determining the influence that sexual media use has on sexual quality.

\section{Congruence of Use Patterns}

Previous research has shown the importance of considering whether couples use sexual media alone or together (Maddox, Rhoades, \& Markman, 2011), as discrepant use tends to be problematic in relationships (Willoughby, Carroll, Busby, \& Brown, 2016). Although studies have shown that women's pornography use is not uncommon (Carroll et al., 2008; Regnerus et al., 2016), the typical reported discrepancy in sexual media use is the heterosexual couple with the man using pornography more often than the woman (Carroll, Busby, Willoughby, \& Brown, 2017; Petersen \& Hyde, 2010). Congruency in use could be important to consider for findings such as sexual media leading to arousal problems (Park et al., 2016) and higher reported intimacy (Kohut et al., 2017). A detailed analysis of the literature surrounding sexual media, arousal, erectile dysfunction, and intimacy is not our purpose here. We simply suggest that we cannot fully understand the extent that content depicted in sexual media might influence arousal and intimacy in a sexual relationship without accounting for couple context.

Viewing sexual media alone rather than with a partner may reinforce arousal to a sexual stimulus without having a partner present. From a learning perspective (e.g., Bandura, 1977; Pavlov, 1927; Skinner, 1938), when sexual media is used in solitude, arousal may become strongly conditioned to sexual media and deconditioned from the relational context. Thus, some individuals may function effectively autoerotically, but not relationally (e.g., Voon et al., 2014). Daneback et al. (2009) provided some empirical support for this idea, showing that in relationships where only the man used sexual media, he reported higher difficulty with arousal. This association was not consistent when both partners used the material. Despite erectile dysfunction not generally being associated with sexual media use (Landripet \& Stulhofer, 2015), enough individuals have spoken out on the connection (e.g., Park et al., 2016; Voon et al., 2014; Wright et al., 2017a) that careful consideration of contextual factors is needed to distinguish between why some users of sexual media report erectile dysfunction during sex with a partner while others report enhanced arousal (e.g., Kohut et al., 2017; Prause \& Pfaus, 2015).

Despite empirical findings supporting our assertion that sexual media scripts are incongruent with sexual intimacy (Sun, Bridges, Johnson, \& Ezzell, 2016), some individuals report that sexual media use positively influences their sexual intimacy (Kohut et al., 2017). Although we have argued that the content of each type of sexual media in and of itself presents scripts incongruent with intimacy, the positive couple process surrounding congruent sexual media use may be the true variable promoting reports of increased intimacy. Similar to associations between sexual media use and arousal, researchers should carefully consider the context of use when considering why some sexual media users report it enhances intimacy, particularly since no script in our identified sexual media typology has any congruence with the definition we have given for intimacy. Also, research should carefully consider the manner in which sexual intimacy is operationalized, as studies tend to define the construct differently (e.g., Kohut et al., 2017; Pascoal et al., 2014; Schnarch, 1991; Sun et al., 2016). In cases where participants simply refer to sexual intimacy, sometimes no definition is given at all (e.g., Kohut et al., 2017; Pascoal et al., 2014). Different definitions lead to different conclusions.

\section{Congruence of Script Application}

Another important factor to consider is the congruence of couples' script application (Campbell \& Kohut, 2017), meaning whether each individual's sexual media script overlaps with what actually takes place in the sexual relationship (Stulhofer et al., 2010). Couples may have congruent sexual media viewing patterns, yet still differ in their application of scripts found within any sexual media type. Acknowledging the types of content viewed is especially important when considering congruency of script application. For example, both partners might apply the script from sexually explicit media, but diverge in applying paraphilic sexual media. Some empirical research has already suggested that the lack of overlap in applying paraphilic scripts can be problematic (Stulhofer et al., 2010). If couples are unable to agree on which scripts to carry out in the relationship, the tension within the sexual relationship could lead to a negative impact on any or all of the sexual quality outcomes we have listed.

For the congruency of script application, a sexual quality outcome of particular note is sexual technique. We have already explained how explicit sexual and paraphilic sexual media present a message that can enhance someone's repertoire of sexual acts. However, if discrepancies exist between partners in applying sexual scripts, couples could struggle in knowing which sexual practices to employ. For example, those that congruently apply the paraphilic media script may be less likely to experience a negative outcome for something like sexual technique, due to the combination of content that provides a repertoire for new sexual practices and the partners' script application congruence. If partners are not congruent in their script application of paraphilic sexual media, the partner who wishes to apply the paraphilic sexual media script may be frustrated with a knowledge of sexual practices she or he is not permitted to employ in the relationship. The coercion script found in paraphilic sexual media may be particularly problematic here, as an individual may coerce a partner into unwanted sexual activity. Altogether, 
when couples are congruent in sexual script application, sexual media's more objective influence in shaping sexual scripts and thereby sexual quality is retained. For example, with congruent script application, the scripts' positive association with factors for short-term sexual quality and negative association with factors for long-term sexual quality will be held constant. However, wherever partners are in disagreement about sexual scripts from any sexual media type, that discrepancy can influence couple processes in a way that dyads report an amplified negative impact on long-term sexual quality and perhaps even deficits in short-term sexual quality (although in these cases the apparent culprit is the contextual variable).

\section{Moral Paradigms}

Another couple contextual factor that should be considered is moral paradigms, as a growing body of research suggests that moral paradigms can amplify reported negative effects of sexual media (e.g., Grubbs, Exline, Pargament, Hook, \& Carlisle, 2015; Leonhardt, Willoughby, \& YoungPetersen, 2018; Ley, Prause, \& Finn, 2014; Nelson, PadillaWalker, \& Carroll, 2010). Moral paradigms stigmatizing sexual media use are often anchored in religious teaching (e.g., Ley et al., 2014; Nelson et al., 2010). These teachings typically value enduring, companionate marital and family relationships (Burr, Marks, \& Day, 2012), likely giving priority to long-term relational sexual quality over shortterm erotic sexual quality. Relationships where one or both partners espouse these relational moral paradigms may be more sensitized to incongruences between messages of all types of sexual media and long-term, relational sexuality. Perhaps partially due to that reason, some couples consider a partner's use of sexual media to be an infringement of relationship boundaries and a threat to trust (Zitzman \& Butler, 2009). Some view it as such an intense threat that it constitutes infidelity (Whitty, 2003; Zitzman \& Butler, 2009). With a moral paradigm holding relational sexuality as the highest ideal and either/both in the relationship finding use of sexual media to be an infringement of relationship boundaries, it seems likely that any sexual media use in such a context would be experienced as detrimental for short as well as long-term sexual quality.

\section{Summary}

In addition to the factors that moderate sexual script application (exclusivity, formativeness, resonance, and reinforcement), couple contextual factors can also moderate how these scripts influence sexual outcomes. Researchers should pay attention to couples' congruency of sexual media use, script application, and moral paradigms in predicting the magnitude of influence of sexual media use on sexual quality outcomes.
As we have demonstrated that the content of sexual media types is congruent with pursuing short-term sexual quality and incongruent with pursuing long-term sexual quality, the presence or absence of couple context moderators can hold these outcomes constant or, as in some cases we have illustrated, likely amplify detriment to long-term sexual quality and reverse the usual enhancement of short-term sexual quality. Our identified contextual variables are important to consider because the application of identified sexual media scripts is not solely responsible for positively influencing long-term sexual quality or negatively influencing short-term sexual quality. Scenarios where couples report inconsistencies with our theoretical assertions (e.g., sexual media resulting in higher intimacy; Kohut et al., 2017) are likely due to contextual variables (e.g., positive couples process surrounding a shared activity) being the true predictor of the outcome, rather than the actual use of sexual media. We do not see evidence suggesting that congruence in use, script application, or moral paradigms will fully dissipate the objective influence of viewing sexual media on sexual quality (stemming from sexual scripting). Overall, to understand how different types of sexual media use influence short-term versus longterm sexual quality, moderators of sexual script application and couple context are needed.

\section{Conclusion}

Suggestive sexual media, explicit sexual media, and paraphilic sexual media form a rough typology of sexual content and each type is differentiated in terms of the sexual script formed therefrom. Overall, sexual media scripts are congruent with pursuing short-term sexual quality, but incongruent with pursuing long-term sexual quality. Additionally, each type of sexual media uniquely predicts a range of factors relating differentially to short-term versus long-term sexual quality. However, the extent of sexual script application and couple context should be considered in assessing sexual media's ultimate impact. By considering all these factors simultaneously, we believe our model provides the most comprehensive understanding to date for how and why sexual media use can differentially influence short-term and long-term sexual quality.

\section{Caveats and Future Directions}

We hope this framework provides a starting point for researchers to assess different types of sexual content and to conceptualize and measure sexual quality in a carefully nuanced manner. In addition to the sexual content, we have acknowledged in our review, other types of sexual content may present unique scripts that deserve additional consideration. For example, a type of sexual media may exist that is not explicit, yet insinuates sexual 
acts, blurring the lines between suggestive sexual media and explicit sexual media. Additionally, researchers should carefully consider whether their research question is best answered by employing a typology approach (e.g., sexually suggestive media versus sexually explicit media) similar to the one we have suggested, or a more variable centric approach focused on a highly specific sexual script (e.g., the script of eroticism). The typology approach would accept the multifaceted nature of sexual media, and presentation of several scripts simultaneously, while the specific script approach might allow a more specified evaluation of a particular script.

Admittedly, just as Fisher (1998) suggested that motivations for sexual drive, attraction, and attachment are interrelated, we similarly judge that factors distinctly contributing to short-term versus long-term sexual quality are also interrelated. For example, sexual openness and sexual communication represent distinct factors. Yet, higher sexual openness is likely to lead to higher comfort surrounding certain aspects of sexual communication (Kelly, Strassberg, \& Turner, 2004). This is just one example of an interrelation that is important to consider in future research, as our model focuses principally on hypothesized primary effects on sexual quality. Yet, in reality, indirect effects likely also exist. We also acknowledge that many ideas in this framework are in need of additional empirical testing. In just one example, although theoretical writings have suggested incompatibility between sexual objectification and intimacy (e.g., Brooks, 1995), empirical work addressing this issue is lacking.

\section{Implications}

Most individuals report stronger motivations in favor of longterm committed relationships than sexual experiences that may be as short as a one-night stand (Jackson \& Kirkpatrick, 2007). For that reason, as researchers we have some concerns about how the messages presented in several forms of sexual media can negatively influence long-term sexual quality. This may be of less concern for those whose goals center on shortterm sexual quality, but even infrequent sexual media use likely brings subtle scripts into the relationship that decrease the likelihood of attaining long-term sexual quality, particularly in the absence of countervailing scripts (Steele, 1999; Wright, 2011). With that in mind, we have a number of recommendations for therapists, religious communities, educators, and parents.

Therapists should carefully consult with couples to determine what they are seeking from their sexual relationship before advising the use of sexual media. Therapists may be able to defend viewing sexual media when the couple's focus is shortterm sexual quality, as studies are suggesting that it can increase sexual openness (Weinberg et al., 2010) and provide ideas for sexual technique (Kohut \& Fisher, 2013). However, therapists should consider caveating that support with the caution that sexual media may be harmful to the couple's long-term sexual quality, as studies are suggesting that sexual media can be harmful to intimacy (Sun et al., 2016) and communication (Wright et al., 2017a) in the sexual relationship. Particularly when counseling couples who have been together for an extended period of time, it may be beneficial for therapists to use our framework to illustrate the distinction between short-term and long-term sexual quality factors, the multifaceted (physical, emotional, and relational) nature of sexual health, and then to help them understand the path to their desired goals.

We hope religious communities can benefit from using our framework, as research has suggested these communities have the potential to shape views about sexuality (Hernandez, Mahoney, \& Pargament, 2014). As mentioned, religious individuals often idealize long-term marital relationships (Burr et al., 2012) and have moral reservations against sexual media (e.g., Grubbs et al., 2015; Nelson et al., 2010). Our framework might assist individuals in religious communities in articulating the type of sexual relationship they are pursuing, and help them educate this understanding to youth. We suggest this framework may also help them better understand diverging claims on how sexual media use influences sexuality. Our hope is that religious communities utilize this framework to engage in positive conversations about the kind of sexual relationship they typically idealize and the factors that support it (Hernandez et al., 2014).

Sexual education and media literacy programs could also benefit from utilizing our framework (e.g., Albury, 2014). The framework can be a conversation starter for youth to identify what they want to pursue in a sexual relationship, as well as consider the congruence or incongruence of sexual media with the type of sexual quality they want to pursue. Some research has already suggested that these educational programs can reduce the likelihood of sexually explicit media forming harmful scripts, by helping youth understand the extent that depictions in sexual media are unrealistic and degrading (Bengry-Howell, 2012; Haste, 2013). One specific study found that attending pornography literacy education mitigated, though not entirely eliminated the connection between viewing explicit sexual media and developing views that women are sex objects (Vandenbosch \& van Oosten, 2017). This suggests that education programs may provide some countervailing scripts to sexual media's more harmful messages. However, consistent with our model, the effect does not seem to completely disappear.

Religious communities and various programs can have a role in educating healthy sexual development. Yet their lesser likelihood of having a formative influence often makes them supplementary to parents in shaping healthy sexual scripts, insofar as parents take advantage of early opportunities with children. Unfortunately, parents often do not take advantage of early opportunities to adequately educate their children on what constitutes a healthy sexual relationship (Martin \& Luke, 2010). This is problematic, considering some children access sexualized 
messages at an early age (Sabina et al., 2008) and are limited in their ability to distinguish between fantasy and reality (Murray et al., 2006) when viewing messages (Fritz \& Paul, 2017; Klaassen \& Peter, 2015; Ward, 2016) that can impede the likelihood of developing long-term sexual quality (e.g., Wright et al., 2017a; Sun et al., 2016). Considering the increased likelihood of various sexual media having a formative influence in shaping children's sexual scripts, we call on parents to take better advantage of the opportunity to shape children's understandings of sexuality. We hope our framework provides parents with a resource to help children solidify a formative and enduring script that can mitigate the influence of scripts running counter to long-term sexual quality (Rasmussen et al., 2015).

As researchers, therapists, educators, and parents we must face the empirical and measurement reality that the impact of sexual media of all types and their associated scripts can be confounded in the crosscurrents of short-term and long-term sexual quality. The complex combination of considering actual content depicted, distinction between factors for sexual quality, and layers of moderating variables can help us understand why some people report no effect from viewing sexual media (e.g., Kohut et al., 2017; Muusses et al., 2015), while others report benefits (Daneback, et al., 2009; Kohut \& Fisher, 2013; Kohut et al., 2017; Olmstead, et al., 2013), and yet others report harm (Lambert et al., 2012; Vandenbosch \& Eggermont, 2012; Zurbriggen et al., 2011). With a wide variety of reported outcomes from sexual media use (Kohut et al., 2017), we understand how considering the relation of sexual media to sexual health can be a polarizing issue for many individuals. By highlighting the nuances in the relationship between viewing sexual media and sexual quality, we can better explain the diversity of findings in the literature and also, in the acknowledgement of that complexity, provide a basis for respectful and helpful conversations in private and public spheres. With full consideration of these factors, we can better capture variations between sexual media's subtle to substantial influence on sexual quality and perhaps increase consideration of the type of sexual relationship we want to pursue and promote.

\section{References}

Albury, K. (2014). Porn and sex education, porn as sex education. Porn Studies, 1, 172-181.

Bandura, A. (1977). Social learning theory. Englewood Cliffs, NJ: Prentice Hall.

Baumeister, R. F., \& Tice, D. M. (2001). The social dimension of sex. Boston, MA: Allyn \& Bacon.

Bengry-Howell, A. (2012). Planet porn: A resource pack for working with teens around porn. Sex Education, 12, 370-372.

Berg, J. H., \& Derlgega, V. J. (1987). Self-disclosure: Theory, research, and therapy. New York: Plenum Press.

Braithwaite, S. R., Coulson, G., Keddington, K., \& Fincham, F. D. (2015). The influence of pornography on sexual scripts and hooking up among emerging adults in college. Archive of Sexual Behavior, 44, 111-123.

Bridges, A. J., \& Morokoff, P. J. (2011). Sexual media use and relational satisfaction in heterosexual couples. Personal Relationships, 18, $562-585$.

Bridges, A. J., Wosnitzer, R., Scharrer, E., Sun, C., \& Liberman, R. (2010). Aggression and sexual behavior in best-selling pornography videos: A content analysis update. Violence Against Women, $16,1065-1085$.

Bronner, G., \& Ben-Zion, I. Z. (2014). Unusual masturbatory practice as an etiological factor in the diagnosis and treatment of sexual dysfunction in young men. Journal of Sexual Medicine, 11, $1798-1806$.

Brooks, G. R. (1995). The Jossey-Bass social and behavioral science series. The centerfold syndrome: How men can overcome objectification and achieve intimacy with women. San Francisco, CA: Jossey-Bass.

Burgess, M., Stermer, S. P., \& Burgess, S. R. (2007). Sex, lies, and video games: The portrayal of male and female characters on video game covers. Sex Roles, 57, 419-433.

Burr, W. R., Marks, L. D., \& Day, R. D. (2012). Sacred matters: Religion and spirituality in families. New York, NY: Taylor \& Francis Group.

Campbell, L., \& Kohut, T. (2017). The use and effects of pornography in romantic relationships. Current Opinion in Psychology, 13, 6-10.

Carroll, J. S., Busby, D. M., Willoughby, B. J., \& Brown, C. C. (2017). The porn gap: Differences in men's and women's pornography patterns in couple relationships. Journal of Couple \& Relationship Therapy, 16, 146-163.

Carroll, J. S., Padilla-Walker, L. M., Nelson, L. J., Olson, C. D., Barry, C., \& Madsen, S. D. (2008). Generation XXX: Pornography acceptance and use among emerging adults. Journal of Adolescent Research, 23, 6-30.

Clark, M. S., \& Mills, J. (2012). Communcal (and exchange) relationships. In P. A. M. Van Lange, A. W. Kruglanski, \& E. T. Higgins (Eds.), Handbook of theories of social psychology (pp. 232-250). Thousand Oaks, CA: Sage.

Colson, M., Lemaire, A., Pinton, P., Hamidi, K., \& Klein, P. (2006). Sexual behaviors and mental perception, satisfaction and expectations of sex life in men and women in France. Journal of Sexual Medicine, 3, 121-131.

Conley, T., \& Ramsey, L. (2011). Killing us softly? Investigating portrayals of women and men in contemporary magazine advertisements. Psychology of Women Quarterly, 35, 469-478.

Cooper, A., Delmonico, D. L., \& Burg, R. (2000). Cybersex users, abusers, and compulsives: New findings and implications. Sexual Addiction and Compulsivity, 7, 5-29.

Cooper, M. L., Pioli, M., Levitt, A., Talley, A. E., Micheas, L., \& Collins, N. L. (2006). Attachment styles, sex motives, and sexual behavior: Evidence for gender-specific expressions of attachment dynamics. In M. Mikulincer \& G. S. Goodman (Eds.), Dynamics of romantic love: Attachment, caregiving, and sex (pp. 243-274). New York: Guilford.

Crawley, J. N., \& Mclean, S. (1996). Neuropeptides: Basic and clinical advances. New York: New York Academy of Sciences.

Daneback, K., Traeen, B., \& Mansson, S. (2009). Use of pornography in a random sample of Norwegian heterosexual couples. Archives of Sexual Behavior, 38, 746-753.

Elise, D. (2017). Moving from within the maternal: The choreography of analytic eroticism. Journal of the American Psychoanalytic Association, 65, 33-60.

Fisher, H. E. (1998). Lust, attraction, and attachment in mammalian reproduction. Human Nature, 9, 23-52.

Fisher, H. E. (2006). The drive to love: The neural mechanism for mate selection. In R. J. Sternberg \& K. Weis (Eds.), The new psychology of love (pp. 87-115). New Haven, CT: Yale University Press. 
Fisher, H. E., Aron, A., Mashek, D., Li, H., \& Brown, L. L. (2002). Defining the brain systems of lust, romantic attraction, and attachment. Archives of Sexual Behavior, 31, 413-419.

Fredrickson, B. L., Roberts, T., Noll, S., Quinn, D., \& Twenge, J. (1998). That swimsuit becomes you: Sex differences in self-objectification, restrained eating, and math performance. Journal of Personality and Social Psychology, 75, 269-284.

Frisby, C. M., \& Aubrey, J. S. (2012). Race and genre in the use of sexual objectification in female artists' music videos. Howard Journal of Communications, 23, 66-87.

Fritz, N., \& Paul, B. (2017). From orgasms to spanking: A content analysis of the agentic and objectifying sexual scripts in feminist, for women, and mainstream pornography. Sex Roles, 77, 639-652.

Frost, D. M., McClelland, S. I., \& Dettmann, M. (2017). Sexual closeness discrepancies: What they are and why they matter for sexual well-being in romantic relationships. Archives of Sexual Behavior, 46, 2353-2364.

Fyfe, B. (1979). Effects of sexual enhancement workshop on young adults. Journal of Clinical Psychology, 35, 873-875.

Gable, S. L., \& Impett, E. A. (2012). Approach and avoidance motives and close relationships. Social and Personality Psychology Compass, 6, 95-108.

Gagnon, J. H., \& Simon, W. (1973). Sexual conduct: The social sources of human sexuality. Chicago, IL: Aldine Books.

Gerbner, G. (1998). Cultivation analysis: An overview. Mass Communication and Society, 1, 175-194.

Grubbs, J. B., Braden, A. L., Kraus, S. W., Wilt, J. A., \& Wright, P. J. (2017). Pornography and pleasure-seeking: Toward a hedonic reinforcement model. Retrieved from psyarxiv.com/jevb7. Accessed 30 March 2018.

Grubbs, J. B., Exline, J. J., Pargament, K. I., Hook, J. N., \& Carlisle, R. D. (2015). Transgression as addiction: Religiosity and moral disapproval as predictors of perceived addiction to pornography. Archives of Sexual Behavior, 44, 125-136.

Hald, G. M., \& Malamuth, N. (2008). Self-perceived effects of pornography consumption. Archives of Sexual Behavior, 37, 614-625.

Hald, G. M., \& Štulhofer, A. (2016). What types of pornography do people use and do they cluster? Assessing types and categories of pornography consumption in a large-scale online sample. Journal of Sex Research, 53, 849-859.

Haste, P. (2013). Sex education and masculinity: The "problem" of boys. Gender and Education, 25, 515-527.

Hatton, E., \& Trautner, M. N. (2011). Equal opportunity objectification? The sexualization of men and women on the cover of Rolling Stone. Sexuality and Culture, 15, 256-278.

Herbert, J. (1996). Sexuality, stress and the chemical architecture of the brain. Annual Review of Sex Research, 7, 1-44.

Hernandez, K. M., Mahoney, A., \& Pargament, K. I. (2014). Sexuality and religion. In D. L. Tolman \& L. M. Diamond (Eds.), APA handbook of psychology and sexuality (Vol. 2, pp. 425-447). Contextual approaches. Washington, DC: American Psychological Association.

Huesmann, L. R. (1988). An information processing model for the development of aggression. Aggressive Behavior, 14, 13-24.

Jackson, J. J., \& Kirkpatrick, L. A. (2007). A structure and measurement of human mating strategies: Toward a multidimensional model of sociosexuality. Evolution and Human Behavior, 28, 382-391.

Kelly, M. P., Strassberg, D. S., \& Turner, C. M. (2004). Communication and associated relationship issues in female anorgasmia. Journal of Sex and Marital Therapy, 30, 263-276.

Klaassen, M. J. E., \& Peter, J. (2015). Gender (in)equality in internet pornography: A content analysis of popular pornographic Internet videos. Journal of Sex Research, 52, 721-735.

Kleinplatz, P. J., Ménard, A. D., Paquet, M. P., Paradis, N., Campbell, M., Zuccarino, D., \& Mehak, L. (2009). The components of optimal sexuality: A portrait of "great sex". Canadian Journal of Human Sexuality, 18, 1-13.

Kohut, T. (2014). An empirical investigation of the concept of "pornography”. Retrieved from http://ir.lib.uwo.ca/etd/2063/. Accessed 30 March 2018.

Kohut, T., \& Fisher, W. A. (2013). The impact of brief exposure to sexually explicit video clips on partnered female clitoral selfstimulation, orgasm and sexual satisfaction. Canadian Journal of Human Sexuality, 22, 40-50.

Kohut, T., Fisher, W. A., \& Campbell, L. (2017). Perceived effects of pornography on the couple relationship: Initial findings of openended, participant-informed, "bottom-up" research. Archives of Sexual Behavior, 46, 585-602.

Lambert, N. M., Negash, S., Stillman, T. F., Olmstead, S. B., \& Fincham, F. D. (2012). A love that doesn't last: Pornography consumption and weakened commitment to one's romantic partner. Journal of Social and Clinical Psychology, 31, 410-438.

Landripet, I., \& Stulhofer, A. (2015). Is pornography use associated with sexual difficulties and dysfunctions among younger heterosexual men? Journal of Sexual Medicine, 12, 1136-1139.

Leonhardt, N. D., \& Willoughby, B. J. (2017). Pornography, provocative sexual media, and their differing associations with multiple aspects of sexual satisfaction. Journal of Social and Personal Relationships. https://doi.org/10.1177/0265-407517739162.

Leonhardt, N. D., \& Willoughby, B. J. (2018). Longitudinal links between pornography use, marital importance, and permissive sexuality during emerging adulthood. Marriage \& Family Review, $54,64-84$.

Leonhardt, N. D., Willoughby, B. J., \& Young-Petersen, B. (2018). Damaged goods: Perception of pornography addiction as a mediator between religiosity and relationship anxiety surrounding pornography use. Journal of Sex Research, 55, 357-368.

Ley, D., Prause, N., \& Finn, P. (2014). The emperor has no clothes: A review of the "pornography addiction" model. Current Sexual Health Reports, 6, 1-12.

Lofgren-Martenson, L., \& Mansson, S. A. (2010). Lust, love, and life: A qualitative study of Swedish adolescents' perceptions and experiences with pornography. Journal of Sex Research, 47, 568-579.

Maddox, A. M., Rhoades, G. K., \& Markman, H. J. (2011). Viewing sexually-explicit materials alone or together: Associations with relationship quality. Archives of Sexual Behavior, 40, 441-448.

Martin, K. A., \& Luke, K. (2010). Gender differences in the ABC's of the birds and the bees: What mothers teach young children about sexuality and reproduction. Sex Roles, 62, 278-291.

McCarthy, B., \& Thestrup, M. (2009). Men, intimacy, and eroticism. Journal of Sexual Medicine, 6, 588-594.

McClelland, S. I. (2010). Intimate justice: A critical analysis of sexual satisfaction. Social and Personality Psychology Compass, 4, $663-680$.

McKee, A. (2005). The objectification of women in mainstream pornographic videos in Australia. Journal of Sex Research, 42, $277-290$

McKee, A. (2015). Methodological issues in defining aggression for content analyses of sexually explicit material. Archives of Sexual Behavior, 44, 81-87.

Menard, A. D., \& Kleinplatz, P. J. (2008). Twenty-one moves guaranteed to make his thighs go up in flames: Depictions of "great sex" in popular magazines. Sexuality and Culture, 12, 1-20.

Mikulincer, M., \& Shaver, P. R. (2016). Attachment in adulthood, second edition: Structure, dynamics, and change. New York, NY: The Guilford Press.

Montesi, J. L., Conner, B. T., Gordon, E. A., Fauber, R. L., Kim, K. H., \& Heimberg, R. G. (2013). On the relationship among social anxiety, intimacy, sexual communication, and sexual satisfaction in young couples. Archives of Sexual Behavior, 42, 81-91. 
Morton, H., \& Gorzalka, B. B. (2015). Role of partner novelty in sexual functioning: A review. Journal of Sex and Marital Therapy, 41, 593-609.

Muise, A., \& Impett, E. A. (2015). Good, giving, and game: The relationships benefits of communal sexual motivation. Social Psychological and Personality Sciences, 6, 164-172.

Muise, A., Impett, E. A., Kogan, A., \& Desmarais, S. (2013). Keeping the spark alive: Being motivated to meet a partner's sexual needs sustains sexual desire in long-term romantic relationships. Social Psychological and Personality Science, 4, 267-273.

Murray, J. P., Liotti, M., Ingmundson, P. T., Mayberg, H. S., Pu, Y., Zamarripa, F., et al. (2006). Children's brain activations while viewing televised violence revealed by fMRI. Media Psychology, 8, 25-37.

Muusses, L. D., Kerkhof, P., \& Finkenauer, C. (2015). Internet pornography and relationship quality: A longitudinal study of within and between partner effects of adjustment, sexual satisfaction, and sexually explicit internet material among newly-weds. Computers in Human Behavior, 45, 77-84.

Nelson, L. J., Padilla-Walker, L. M., \& Carroll, J. S. (2010). "I believe it is wrong but I still do it": A comparison of religious young men who do versus do not use pornography. Psychology of Religion and Spirituality, 2, 136-147.

Nemetz, G. H., Craig, K. D., \& Reith, G. (1978). Treatment of female sexual dysfunction through symbolic modeling. Journal of Consulting and Clinical Psychology, 46, 62-73.

Newmahr, S. (2014). Eroticism as embodied emotion: The erotics of renaissance faire. Symbolic Interaction, 37, 209-225.

Olmstead, S. B., Negash, S., Pasley, K., \& Fincham, F. D. (2013). Emerging adults' expectations for pornography use in the context of future committed romantic relationships: A qualitative study. Archives of Sexual Behavior, 42, 625-635.

Park, B. Y., Wilson, G., Berger, J., Christman, M., Reina, B., Bishop, F., et al. (2016). Is internet pornography causing sexual dysfunctions? A review with clinical reports. Behavioral Science, 6, 1-25.

Pascoal, P. M., Narciso, I. D., \& Pereira, N. M. (2014). What is sexual satisfaction? Thematic analysis of lay people's definitions. Journal of Sex Research, 51, 22-30.

Pavlov, I. P. (1927). Conditioned reflexes: An investigation of the physiological activity of the cerebral cortex (G. V. Anrep, Trans.). New York: Dover.

Petersen, J. L., \& Hyde, J. S. (2010). A meta-analytic review of research on gender differences in sexuality, 1993-2007. Psychological Bulletin, 136, 21-38.

Pfaus, J. G., Kippin, T. E., Coria-Avila, G. A., Gelez, H., Afonso, V. M., Ismail, N., \& Parada, M. (2012). Who, what, where, when (and maybe even why)? How the experience of sexual reward connects sexual desire, preference, and performance. Archives of Sexual Behavior, 41, 31-62.

Pfaus, J. G., Scepkowski, L. A., Marson, L., \& Georgiadis, J. R. (2014). Biology of the sexual response. In D. L. Tolman, L. M. Diamond, J. A. Bauermeister, W. H. George, J. G. Pfaus, \& L. M. Ward (Eds.), APA handbook of sexuality and psychology (Vol. 1, pp. 145-203). Person-based approaches. Washington, DC: American Psychological Association.

Prause, N., \& Pfaus, J. (2015). Viewing sexual stimuli associated with greater sexual responsiveness, not erectile dysfunction. Sexual Medicine, 3, 90-98.

Prieler, M., \& Centeno, D. (2013). Gender representation in Philippine television advertisements. Sex Roles, 69, 276-288.

Rasmussen, E. E., Ortiz, R. R., \& White, S. R. (2015). Emerging adults' responses to active mediation of pornography during adolescence. Journal of Children and Media, 9, 160-176.

Regnerus, M. D., Gordon, D., \& Price, J. (2016). Documenting pornography use in America: A comparative analysis of methodological approaches. Journal of Sex Research, 53, 873-881.
Reis, H. T., \& Shaver, P. (1988). Intimacy as an interpersonal process. In S. W. Duck (Ed.), Handbook of personal relationships (pp. 367-389). New York: Wiley.

Rind, B. (2015). Trends in evolutionary explanations for human male same-sex eroticism: A commentary on Riegel (2011). International Journal of Sexual Health, 27, 199-209.

Sabina, C., Wolak, J., \& Finkelhor, D. (2008). The nature and dynamics of internet pornography exposure for youth. CyberPsychology \& Behavior, 11, 169-171.

Schachner, D. A., \& Shaver, P. R. (2004). Attachment dimensions and sexual motives. Personal Relationships, 11, 179-195.

Schnarch, D. M. (1991). Constructing the sexual crucible: An integration of sexual and marital therapy. New York: W. W. Norton Company.

Short, M. B., Black, L., Smith, A. H., Wetterneck, C. T., \& Wells, D. E. (2012). A review of internet pornography use research: Methodology and content from the past 10 years. Cyberpsychology, Behavior, and Social Networking, 15, 13-23.

Skinner, B. F. (1938). The behavior of organisms. New York: Appleton-Century-Crofts.

Stankiewicz, J., \& Rosselli, F. (2008). Women as sex objects and victims in print advertisements. Sex Roles, 58, 579-589.

Starr, C. R., \& Ferguson, G. M. (2012). Sexy dolls, sexy grade-schoolers? Media \& maternal influences on young girls' self-sexualization. Sex Roles, 67, 463-476.

Steele, J. R. (1999). Teenage sexuality and media practice: Factoring in the influences of family, friends, and school. Journal of Sex Research, 36, 331-341.

Stulhofer, A., Busko, V., \& Landripet, I. (2010). Pornography, sexual socialization, and satisfaction among young men. Archives of Sexual Behavior, 39, 168-178.

Sun, C., Bridges, A., Johnson, J. A., \& Ezzell, M. B. (2016). Pornography and the male sexual script: An analysis of consumption and sexual relations. Archives of Sexual Behavior, 45, 983-994.

Vandenbosch, L., \& Eggermont, S. (2012). Understanding sexual objectification: A comprehensive approach toward media exposure and girls' internalization of beauty ideals, self-objectification, and body surveillance. Journal of Communication, 62, 869-887.

Vandenbosch, L., \& van Oosten, J. M. F. (2017). The relationship between online pornography and the sexual objectification of women: The attenuating role of porn literacy education. Journal of Communication, 67, 1015-1036.

Voon, V., Mole, T. B., Banca, P., Porter, L., Morris, L., Mitchell, S., et al. (2014). Neural correlates of sexual cue reactivity in individuals with and without compulsive sexual behaviours. PLoS ONE, 9, e102419. https://doi.org/10.1371/journal.pone.0102419.

Ward, L. M. (2016). Media and sexualization: State of empirical research, 1995-2015. Journal of Sex Research, 53, 560-577.

Weinberg, M. S., Williams, C. J., Kleiner, S., \& Irizarry, Y. (2010). Pornography, normalization, and empowerment. Archives of Sexual Behavior, 39, 1389-1401.

Whitty, M. T. (2003). Pushing the wrong buttons: Men's and women's attitudes toward online and offline infidelity. CyberPsychology \& Behavior, 6, 569-579.

Willoughby, B. J., \& Busby, D. M. (2016). In the eye of the beholder: Exploring variations in the perception of pornography. Journal of Sex Research, 53, 678-688.

Willoughby, B. J., Carroll, J. S., Busby, D. M., \& Brown, C. (2016). Differences in pornography use among romantic couples: Associations with satisfaction, stability, and relationship processes. Archives of Sexual Behavior, 45, 145-158.

Wong, R. (2016). VR porn is here and it's scary how realistic it is. Mashable. Retrieved from http://mashable.com/2016/01/08/naughtyamerica-vr-porn-experience/\#DIUoRXQHbmqt. Accessed 30 March 2018. 
Wright, P. J. (2011). Mass media effects on youth sexual behavior assessing the claim for causality. Annals of the International Communication Association, 35, 353-385.

Wright, P. J., Sun, C., Steffen, N. J., \& Tokunaga, R. S. (2017a). Associative pathways between pornography consumption and reduced sexual satisfaction. Sexual and Relationship Therapy. https://doi. org/10.1080/14681994.2017.1323076.

Wright, P. J., Tokunaga, R. S., Kraus, A., \& Klann, E. (2017b). Pornography consumption and satisfaction: A meta-analysis. Human Communication Research, 43, 315-343.
Zitzman, S. T., \& Butler, M. H. (2009). Wives' experience of husbands' pornography use and concomitant deception as an attachment threat in the adult pair-bond relationship. Sexual Addiction \& Compulsivity, 16, 210-240.

Zurbriggen, E. L., Ramsey, L. R., \& Jaworski, B. K. (2011). Self- and partner-objectification in romantic relationships: Associations with media consumption and relationship satisfaction. Sex Roles, 64, 449-462. 